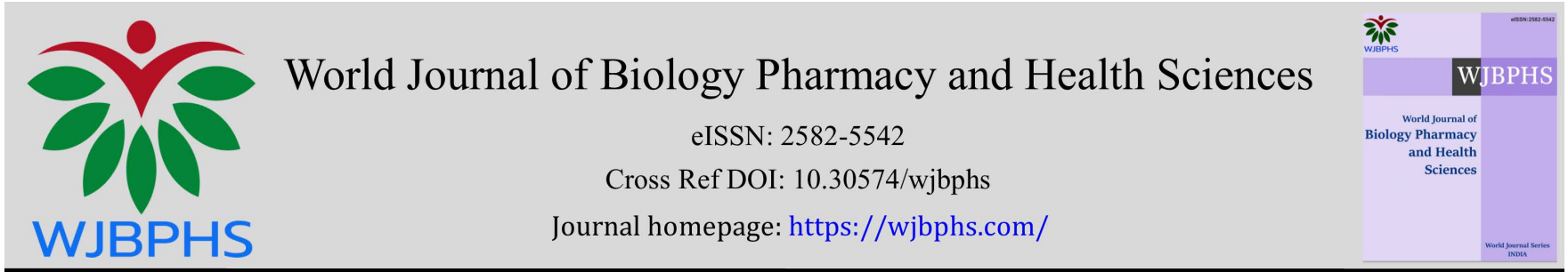

(RESEARCH ARTiCLE)

\title{
Evaluation of antioxidant activity of unpurified and purified datura seed
}

Umang Haribhai Gajjar*, Niralee Kalpeshkumar Velhal, Hetvi Girdharbhai Parikh, Jayrajsinh Bhartbhai Parmar, Yash Bhut and Viral Rupeshbhai Patel

School of Pharmacy, ITM (SLS) Baroda University, Vadodara, Gujarat, India.

World Journal of Biology Pharmacy and Health Sciences, 2021, 08(01), 030-035

Publication history: Received on 27May 2021; revised on 02July 2021; accepted on 06July 2021

Article DOI: https://doi.org/10.30574/wjbphs.2021.7.1.0070

\begin{abstract}
Aim: Evaluation of effect of shodhana process of datura seed (Datura stramonium) antioxidant activity.

Methods: The datura was purified with two different processes viz. cow's urine, and cow's milk by Dolayantra method. Antioxidant activity was evaluated by in-vitro 1,1-Diphenyl-2-picryl hydrazyl (DPPH) radicals scavenging activity and Ferric reducing power ability (FRPA) assay.

Result: cow urine purified datura (CUD) showed a significant effect in inhibiting DPPH, reaching up to $85.96 \%$ at concentration $1000 \mathrm{mcg} / \mathrm{ml}$ and its $\mathrm{IC}_{50}$ was $314.3 \mathrm{mcg} / \mathrm{ml}$ while Unpurified Datura Seed (UD) reaching up to $86.06 \%$ at concentration $1000 \mathrm{mcg} / \mathrm{ml}$ and its IC 50 was $171.73 \mathrm{mcg} / \mathrm{ml}$. The Cow Milk Purified Datura Seed (CMD) extract reach $69.72 \%$ at concentration $1000 \mathrm{mcg} / \mathrm{ml}$ and its IC 50 value was 640 . The IC50 value of Ascorbic acid was $23.35 \mathrm{mcg} / \mathrm{ml}$. CUD showed a significant effect in reduction of ferric ion, reaching up to $85.59 \%$ reduction at concentration 1000 $\mathrm{mcg} / \mathrm{ml}$ and its $\mathrm{EC}_{50}$ was $304.46 \mathrm{mcg} / \mathrm{ml}$ while UD reaching up to $86.11 \%$ at concentration $1000 \mathrm{mcg} / \mathrm{ml}$ and its $\mathrm{EC}_{50}$ was $280.28 \mathrm{mcg} / \mathrm{ml}$. CMD extract reach $52.28 \%$ at concentration $1000 \mathrm{mcg} / \mathrm{ml}$ and its EC 50 value was $1091.3 \mathrm{mcg} / \mathrm{ml}$.
\end{abstract}

Keywords: Datura Seed; Shodhana Process; Antioxidant Activity; phytochemicals

\section{Introduction}

Initially, the researchers focused on phytochemicals and pharmacological investigation of various herbal crude medications and herbal products. Later research focused on extracting and characterizing active phytoconstituents responsible for a variety of pharmacological effects. Several researches were conducted with the goal of reducing toxicity and enhancing efficacy of isolated natural phytocompounds by altering the structures of isolated active phytoconstituents. In compared to pharmacological studies, there has been less investigation on the various qualities of the Ayurvedic medications (Sukumar \& Balakrishna, 1985). For many years, Ayurvedic practitioners have used poisonous natural medications, either in their raw form or through shodhana processes, to treat human ailments. Initially, most therapeutic herbs were regarded to be safe and had no known adverse effects. They are, nevertheless, harmful, according to various studies. These herbs are commonly employed in the treatment of diseases and pathological states, notwithstanding their toxicity. Ayurveda divides herbs into Visha and Upavisha categories (toxic) e.g., Aconite, Nux-vomica (Shastri, 1973). Ayurvedic research not only used mercurial and lead salts in therapy after detoxification, but also created the concept of "Shodhana", which comprises the detoxification of hazardous medicines (Mishra, 2007). Toxic plants can be used with the detoxification procedure, commonly known as shodhana. Traditional shodhana detoxification treatments have been fully explained in the literature and are thought to reduce the toxicity of many harmful plants. A single detoxification technique has been found to be insufficient for the removal of all crude

${ }^{*}$ Corresponding author: Umang Haribhai Gajjar

School of Pharmacy, ITM (SLS) Baroda University, Vadodara, Gujarat, India.

Copyright (C) 2021 Author(s) retain the copyright of this article. This article is published under the terms of the Creative Commons Attribution Liscense 4.0. 
chemicals. The shodhana process has recognized the use of numerous media such as cow milk, cow urine, water, lime, and so on in light of this data (Haridutta, 1954).

Native medicine has been found to be effective in curing human ailments, despite the fact that there is no evidence in the current literature to support the scientific validity of such cleansing techniques. As a result, Ayurvedic shodhana processes may have a qualitative and quantitative effect on the phytochemical profiles of hazardous plants, changing the efficacy and toxicity of herbal medications.

Datura stramonium (D. stramonium) is an annual Solanaceae herb with a wide distribution. One of the most well-known therapeutic herbs from folklore. It's a wild flowering plant that's been investigated as a local source of tropane alkaloids $\left(\mathrm{N}-\mathrm{CH}_{3}\right)$, which include anti-cholinergic medications like atropine and scopolamine. Shiva, a Hindu god, was said to consume Cannabis and Datura. (M. Shagal et al., 2012).

The stripped bark is used to treat swellings, burns, and ulcers, and the leaves are used to form an extract that is taken orally to treat asthma and sinus infections. Some of the plant's therapeutic benefits include anti-inflammatory properties, relaxation of the central nervous system, respiratory decongestion, and treatment of dental and skin problems, alopecia, and toothache relief. It's a psychedelic plant that can kill you if consumed in large quantities. Any portion of the plant can cause a severe anticholinergic reaction, resulting in toxicity and, in rare cases, diagnostic difficulties. Consumption of the berries has been linked to poisoning. After eating 125 seeds, the seeds may be potentially effective as an alternative to atropine for the treatment of muscarinic symptoms of organophosphate toxicity and certain core anticholinergic effects, as they contain the maximum concentration and have a rapid onset of action. The presence of one or more of these chemicals, such as alkaloids, tannins, saponins, and cardiac glycosides, is responsible for the therapeutic characteristics of many plants. The phytochemical screening included saponins, tannins, hormones, alkaloids, flavonoids, phenols, and glycosides. Atropine and scopolamine are depressants that act as competitive antagonists of muscarinic cholinergic receptors in the central nervous system. While the plant is deadly in all sections, the ripe seeds carry the greatest alkaloids. Several incidents of $D$. stramonium poisoning have been reported when these plants are unintentionally ingested. (OA Oseni et al., 2011) Belladonna alkaloids are common in Datura species, and they can cause anticholinergic toxicity both locally and systemically. (Galre , 2008).

\section{Material and methods}

\subsection{Chemicals and Reagents}

Raw datura seed was procured from Sanjivani Ayushdhalay, Bhavnagar, Gujarat and materials for shodhana were procured form local vender of Vadodara, Gujarat, India.

All other chemicals and reagents used in the study were obtained from Ranbaxy chemicals ltd - Delhi, Qualigens chemicals ltd. - Mumbai, India S.D. Fine chemicals - Mumbai.

\subsection{Shodhana Process of Unpurified Datura}

For the shodhana of raw datura, the process recommended by Haridutta (1954) and Kruti et al, (2014) was followed. 25 g Unpurified datura seed was accurately weighed and packed in a cotton cloth. It was dipped in the Dolanyantra containing cow's urine ( $3 \mathrm{~L}$ ) in it. Then this Dolanyantra was heated on a gas stove fire for at least $3 \mathrm{~h}$. After $3 \mathrm{~h}$ the cloth bag was removed and pressed between two palms. The collected cow urine was evaporated and dried. Dried purified datura seed was collected and weighed.

Further, this shodhana process was repeated for unpurified datura with different vehicle, one is cow's milk.

The cow's urine purified datura and cow's milk purified datura were stored for further study.

\subsection{Pharmacological Evaluation}

\subsubsection{In vitro Antioxidant activity of Methanolic extracts of unpurified and purified Datura stramonium seed}

The concept of developing drugs from plants used in indigenous medical system is much older, while in some cases direct links between a local and biomedical use exists, in other cases the relationship is much more complex. 


\subsection{Preparation of extract}

Powder of unpurified and purified Datura seeds (100 gm) were extracted with methanol using soxhlet apparatus. The extracts were concentrated and air-dried and stored in well closed containers in refrigerator till further use.

\subsection{Instrument}

- UV visible double beam Spectrophotometer.

\subsection{Model 1}

1,1-Diphenyl-2-picryl hydrazyl (DPPH) radicals scavenging activity

\subsection{Introduction}

This method was given by brand - Williams, cuvelier and berst and later modified by Sanchez Moreno, larrauri and saura-calixto. It is one of the most extensively used antioxidant assay for plant samples. (Ali S.S., 2008)

This method is based on scavenging of the 1.1- dipheny1-2-picrylhydrazyl radical (DPPH) from the antioxidants. Which produces a decreases in absorbance at $516 \mathrm{~nm}$. When a solution of DPPH is mixed with a substance that can donate a hydrogen atom, the reduced from of radical is generated accompanied by loss of color. This delocalization in the deep violet color of DPPH solution is characterized by measuring absorption of ethanol solution at $520 \mathrm{~nm}$.

Representing the $\mathrm{DPPH}$ radical by $\mathrm{Z}^{*}$ and the donor molecule by $\mathrm{AH}$, the primary reaction is:

$$
Z^{*}+\mathrm{AH} \rightarrow \mathrm{ZH}+A^{*}
$$

\subsection{Chemicals and reagents}

1-1dispheny1-2 -picryl hydrazyl (DPPH). A solution of $1.31 \mathrm{~g} / \mathrm{ml}$ in methanol was made and protected from light by covering the test tubes with aluminium foil.

\subsection{Preparation of sample extracts}

All test extract were taken in range of $10-10001 \mathrm{~g} / \mathrm{ml}$ methanol.

\subsection{Preparation of standard solution}

Ascorbic acid was used as standard. Aliquots of 10-1000 1g/ml in methanol were prepared

\subsection{Procedure}

DPPH solution $150 \mu \mathrm{L}$ was added to $3 \mathrm{ml}$ water and absorbance was taken after 30 minute at $516 \mathrm{~nm}$ for control reading. $150 \mu \mathrm{L}$ of different up to $3 \mathrm{ml}$ with water, the mixture was kept in dark for 30 minutes and absorbance was measured at $516 \mathrm{~nm}$ after 30 minutes.

The $\%$ reduction was calculated as follow,

$$
\% \text { scavenging }=\frac{A_{B} \times A_{A}}{A_{B}} \times 100
$$

Where,

- $\mathrm{A}_{\mathrm{A}}$ is the absorbance of the tested sample after 30 minutes.

- $\mathrm{A}_{\mathrm{B}}$ is the absorbance of control sample.

- $\mathrm{IC}_{50}$ is the concentration required to reduce $\%$ reduction by $50 \%$

The antioxidant oh the extract was expressed as $\mathrm{IC}_{50}$. The $\mathrm{IC}_{50}$ value is the concentration $(\mu \mathrm{g} / \mathrm{ml})$ of extract that inhibits the formation of DPPH radicals by $50 \%$. (Sun Y.P. 2009)

\subsection{Model 2}

Ferric reducing power ability (FRPA) assay: 


\section{Introduction}

Ferric reducing ability assay is a technique to the total antioxidant power interpreted as the reducing capability. The reducing power of plant extract was determined by the method of the capacity of reduce the ferric-ferricyanide complex to the ferrous-ferricyanide complex of Prussian blue was determined by recording the absorbance of the reaction mixture the greater is the reducing power (Oyaizu et al).

\subsection{Chemical and reagents}

- Phosphate buffer: 1.75 gm of potassium ferricyanide was dissolved in $100 \mathrm{ml}$ of distilled water.

- Potassium ferricyanide (1\%):1gm of potassium ferricyanide was dissolved in $100 \mathrm{ml}$ of distilled water.

- Trichloroacetic acid (TCA) (10\%): $10 \mathrm{gm}$ of trichloroacetic acid was dissolved in $100 \mathrm{ml}$ of distilled water. Keep this in cool temperature.

- Ferric chloride $\left(\mathrm{FeCl}_{3}\right)(0.1 \%): 0.1 \mathrm{ml}$ gm of ferric chloride was dissolve in $100 \mathrm{ml}$ of distilled water.

\subsection{Preparation of sample extract}

The methanolic extract above mentioned Aliquots of 200-1000 1g/ml in methanol were prepared.

\subsection{Procedure}

Different concentration of plant extract in $1 \mathrm{ml}$ of distilled water was mixed with phosphate buffer (2.5 ml) and potassium ferricyanide $(2.5 \mathrm{ml})$ and the mixture was incubated at $50 \mathrm{~A} \mathrm{C}$ for $20 \mathrm{~min}$. the upper layer of solution (2.5 ml) was mixed with distilled water $(2.5 \mathrm{ml})$ and $\mathrm{FeCl}_{3}(0.5 \mathrm{ml})$ and the absorbance was measured at $700 \mathrm{~mm}$.

$\mathrm{EC}_{50}$ is the concentration measured to get the $50 \%$ response. The results were plotted as concentration $\mathrm{v} / \mathrm{s} \% \mathrm{reduction}$ and found the regression equation. In the regression equation put the value 50 at the \% reduction and found the concentration which was $\mathrm{EC}_{50}$ of the particular sample. (Sun Y.P., 2009) (Oyaizu et al).

\section{Results and discussion}

\subsection{1,1-Diphenyl-2-picryl hydrazyl (DPPH) radicals scavenging activity}

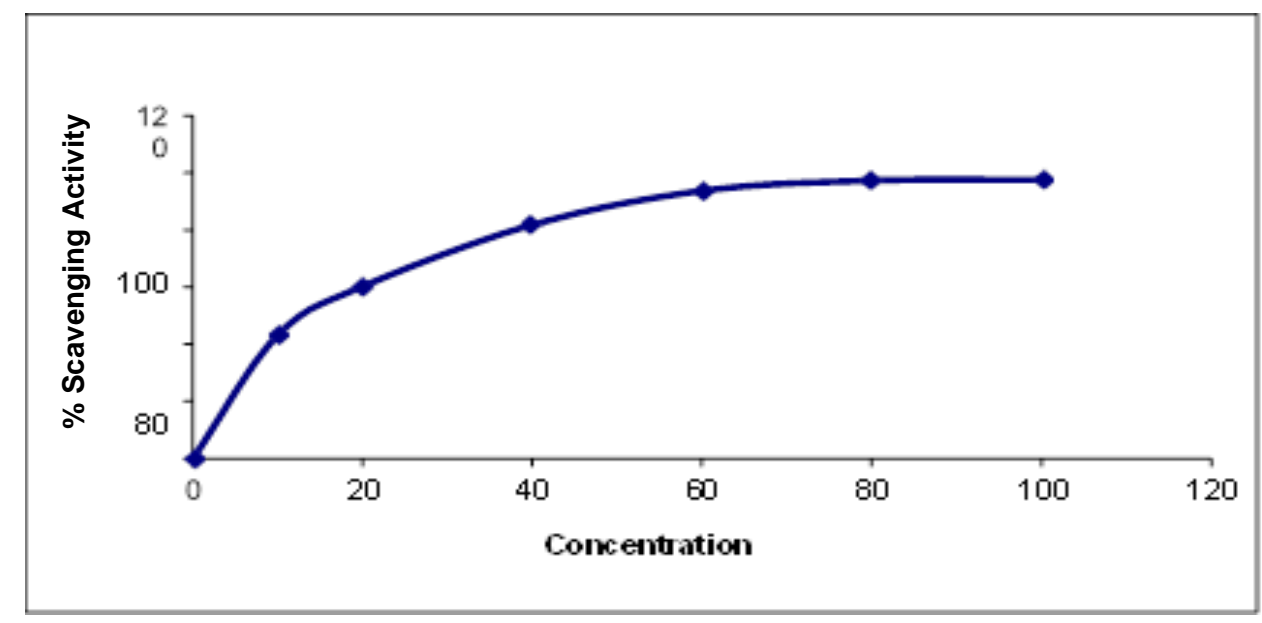

Figure $1 \%$ scavenging effect of Ascorbic acid as a standard

CUD showed a significant effect in inhibiting DPPH, reaching up to $85.96 \%$ at concentration $1000 \mathrm{mcg} / \mathrm{ml}$ and its $\mathrm{IC}$ 50 was $314.3 \mathrm{mcg} / \mathrm{ml}$ while UD reaching up to $86.06 \%$ at concentration $1000 \mathrm{mcg} / \mathrm{ml}$ and its $\mathrm{IC}_{50} \mathrm{was} 171.73 \mathrm{mcg} / \mathrm{ml} . \mathrm{The}$ CMD extract reach $69.72 \%$ at concentration $1000 \mathrm{mcg} / \mathrm{ml}$ and its $\mathrm{IC}_{50}$ value was 640 . The IC 50 value of Ascorbic acid was $23.35 \mathrm{mcg} / \mathrm{ml}$.

Our experiment indicate that UD has high antioxidant activity If we compare the $\mathrm{IC}_{50}$ value ofthe all the samples with the Ascorbic acid, UD shows high power of antioxidant activity, followed by CUD and CMD. 


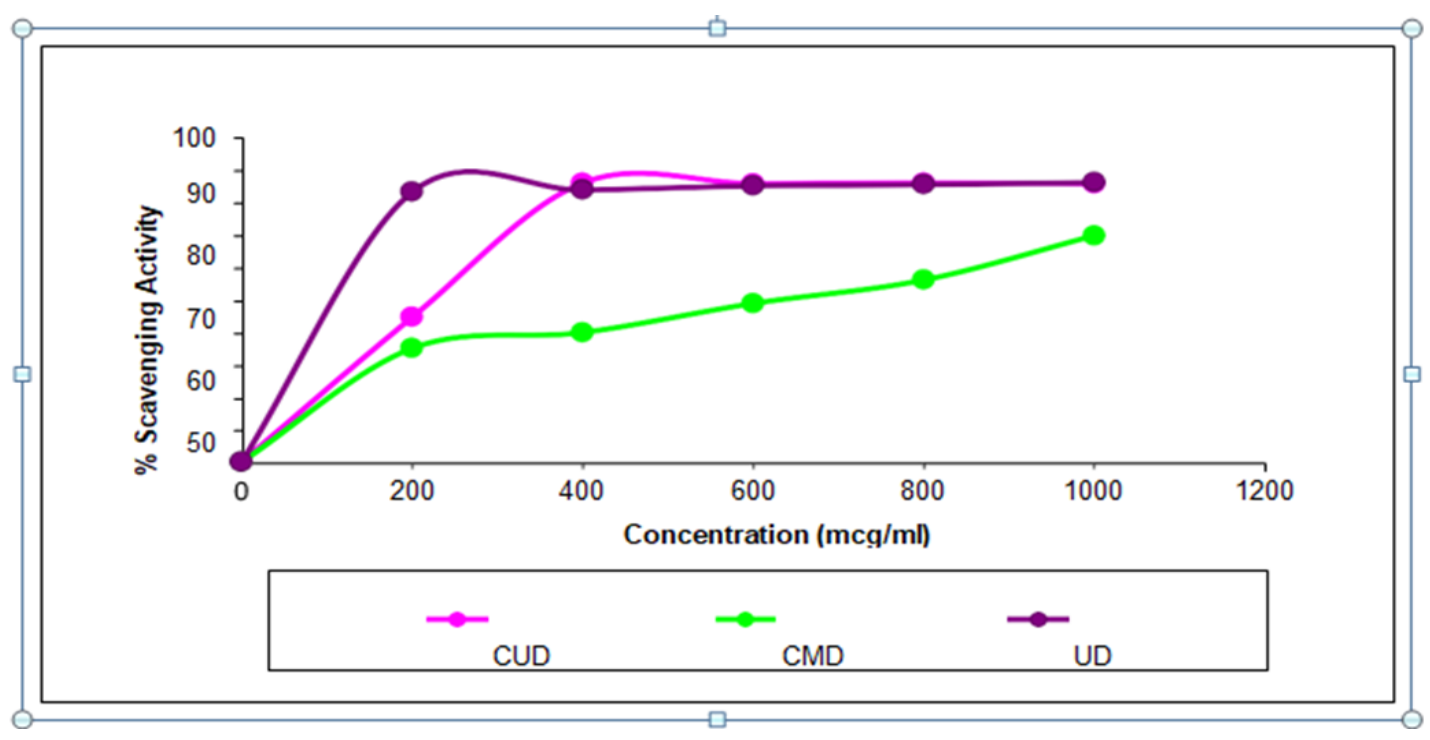

Figure $2 \%$ Scavenging Effect of UD, CUD and CMD

Table 1 IC 50 value of Ascorbic acid, UD, CUD and CMD

\begin{tabular}{|c|c|}
\hline Test Sample & IC $_{50}$ \\
\hline Ascorbic Acid (Std.) & 23.35 \\
\hline UD & 171.73 \\
\hline CUD & 314.3 \\
\hline CMD & 640 \\
\hline
\end{tabular}

CUD showed a significant effect in inhibiting DPPH, reaching up to $85.96 \%$ at concentration $1000 \mathrm{mcg} / \mathrm{ml}$ and its $\mathrm{IC}_{50}$ was $314.3 \mathrm{mcg} / \mathrm{ml}$ while UD reaching up to $86.06 \%$ at concentration $1000 \mathrm{mcg} / \mathrm{ml}$ and its IC 50 was $171.73 \mathrm{mcg} / \mathrm{ml}$. The CMD extract reach $69.72 \%$ at concentration $1000 \mathrm{mcg} / \mathrm{ml}$ and its IC 50 value was 640 . The $\mathrm{IC}_{50}$ value of Ascorbic acid was $23.35 \mathrm{mcg} / \mathrm{ml}$.

Our experiment indicate that UD has high antioxidant activity If we compare the IC $_{50}$ value of the all the samples with the Ascorbic acid, UD shows high power of antioxidant activity, followed by CUD and CMD.

\subsection{Ferric Reducing Power Ability (FRPA) assay}

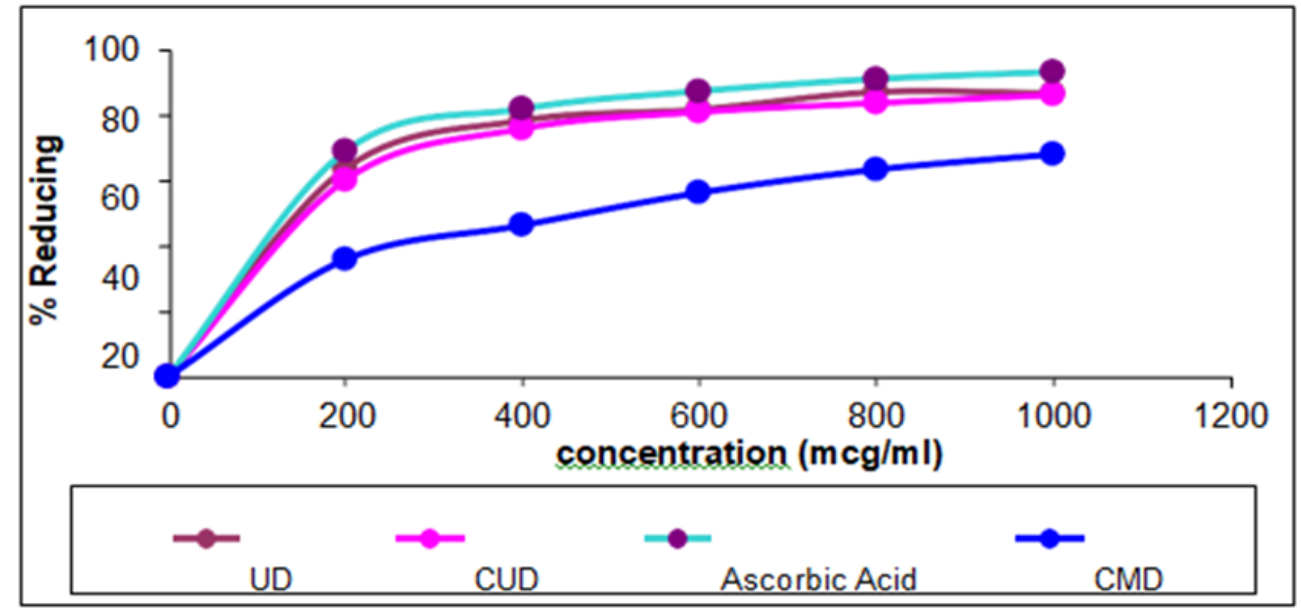

Figure $3 \%$ Reducing Power of Ascorbic acid, UD, CUD and CMD 
Table 2 EC 50 value of Ascorbic acid, UD, CUD and CMD

\begin{tabular}{|c|c|}
\hline Ingredient & $\mathbf{E C}_{\mathbf{5 0}} \mathbf{( \mathbf { m c g } / \mathbf { m l } )}$ \\
\hline Ascorbic Acid (Std.) & 238.51 \\
\hline UD & 280.28 \\
\hline CUD & 304.46 \\
\hline CMD & 1091.30 \\
\hline
\end{tabular}

CUD showed a significant effect in reduction of ferric ion, reaching up to $85.59 \%$ reduction at concentration 1000 $\mathrm{mcg} / \mathrm{ml}$ and its $\mathrm{EC}_{50}$ was $304.46 \mathrm{mcg} / \mathrm{ml}$ while UD reaching up to $86.11 \%$ at concentration $1000 \mathrm{mcg} / \mathrm{ml} \mathrm{and} \mathrm{its} \mathrm{EC}_{50}$ was $280.28 \mathrm{mcg} / \mathrm{ml}$. CMD extract reach $52.28 \%$ at concentration $1000 \mathrm{mcg} / \mathrm{ml}$ and its $\mathrm{EC}_{50}$ value was $1091.3 \mathrm{mcg} / \mathrm{ml}$.

\section{Conclusion}

The purified datura retained antioxidant activity. The best shodhana process among all tested was found to be cow urine purified datura (CUD).

\section{Compliance with ethical standards}

\section{Disclosure of conflict of interest}

No conflict of interest, soul authorship.

\section{References}

[1] Sukumar E, Balakrishna K. Medicinal Gum Resin - Guggul a review, Ancient Science of Life. 1985; 2: $104-112$.

[2] Shastri K.Rastarangini, 9th Edition, Motilal Banarasidas, Varansasi. 1973.

[3] Mishra S. Ayurvedic Rasshtra, Chaukhambha Orientalia, Varanasi. 2007.

[4] Haridutta S. Rasatarangini, Sunderlal Jain Motilal Banarasidas, Varanasi. 1954.

[5] Shagal MH, Modibbo UU, Liman AB. Pharmacological justification for the ethnomedical use of Datura stramonium stem-bark extract in treatment of diseases caused by some pathogenic bacteria. Int Res Pharm Pharmaco. 2012; 2(1):16-19.

[6] Oseni OA, Olarinoye CO, Amoo IA. Studies on chemical compositions and functional properties of thorn apple (Datura stramonium L) Solanaceae. Afric J Food Sci. 2011; 5(2):40-44.

[7] Bhakta Prasad Galre, Monographs on Datura stramonium L, Pharmaceutical and Biomedical sciences. 2008; 2105.

[8] Kruti V, Kinnari D, Prajapati P. Methods of Guggulu Shodhana in Ayurveda - A Review, International Journal of Ayurvedic Medicine. 2014; 5(2): 154-160.

[9] Ali SS, Kasoju N, Luthra A, Singh A, Sharanabasava H, Sahu A, Bora U. Indian medicinal herbs as sources of antioxidants. Food Research International. 2008; 41: 1-15.

[10] Oyaizu M. Antioxidative activities of browning reaction prepared from glucosamine. Japanese Journal of Neutrition Science. 1986; 20: 367-380.

[11] Yu-Ping Sun, Cheng-Chun Chou, Roch-Chui Yu. Antioxidant activity of lactic-fermented Chinese cabbage. Food chemistry. 2009; 115: 912-917. 